\title{
Emulsion PCR made easy
}

\section{Vaishali Verma', Amita Gupta ${ }^{1,2}$ \& Vijay K Chaudhary*,1,2 iD}

${ }^{1}$ Centre for Innovation in Infectious Disease Research, Education \& Training (CIIDRET), University of Delhi South Campus, New Delhi, 110021 , India; ${ }^{2}$ Department of Biochemistry, University of Delhi South Campus, New Delhi, 110021, India; *Author for correspondence: vkchaudhary@south.du.ac.in

BioTechniques 69: 65-69 (July 2020) 10.2144/btn-2019-0161

First draft submitted: 5 December 2019; Accepted for publication: 23 March 2020; Published online: 27 April 2020

\section{ABSTRACT}

Emulsion PCR (ePCR) is an important technique that permits amplification of DNA molecules in physically separated picoliter-volume water-inoil droplets, and thus avoids formation of unproductive chimeras and other artifacts between similar DNA sequences. However, the recovery of ePCR products involves repeated extraction with hazardous organic solvents followed by purification using silica-based columns, making the overall process cumbersome. In this benchmark, we have described a quick ePCR extraction protocol for the purification of ePCR products, which directly employs silica-based DNA purification columns; products purified using this method have been found to be compatible with gene cloning and next-generation sequencing applications. The method described here makes ePCR easy, safe and within the reach of every laboratory.

\section{METHOD SUMMARY}

Here we describe a simplified method for direct breakage of the emulsion using the DNA binding buffer (containing guanidine hydrochloride and isopropanol) that is provided with commonly used silica column-based purification kits, followed by purification of the PCR products using silica columns. This method eliminates the routinely performed multi-step breakage of emulsion and extraction of DNA using hazardous organic solvents, making it simpler and safe for use in any laboratory.

\section{GRAPHICAL ABSTRACT}

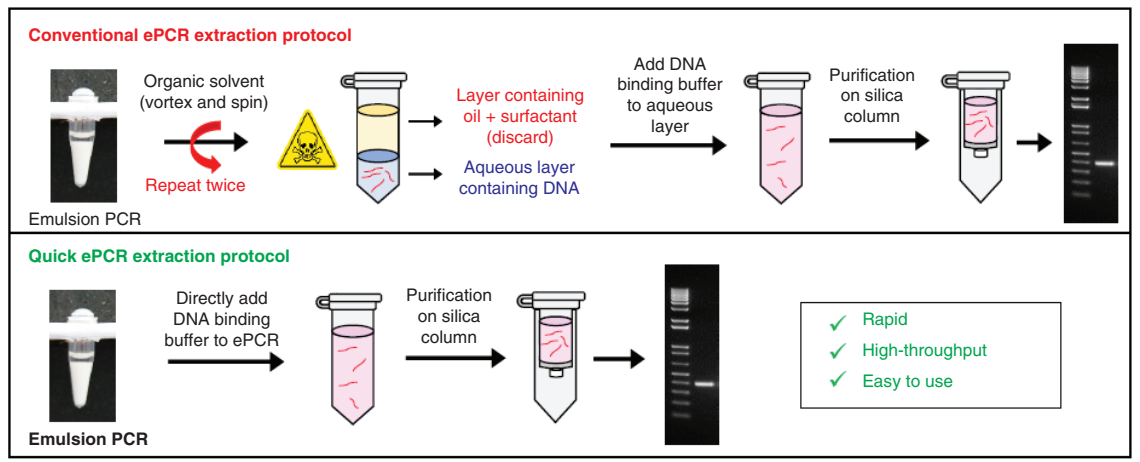

\section{KEYWORDS:}

aptamer $\bullet$ chimerization $\bullet$ emulsion PCR • extraction • next-generation sequencing • silica column purification

Emulsion PCR (ePCR) is a commonly used technology for amplification of DNA molecules in physically separated picoliter-volume water-in-oil droplets that serve as miniaturized 'reaction tubes'. It has been widely exploited for analytical applications such as copy number determination using droplet digital PCR, and preparative-scale applications, such as molecular evolution, genome-scale DNA and aptamer library construction, next-generation sequencing (NGS) for rRNA profiling, and so on [1-12]. The compartmentalization of individual DNA molecules in distinct reaction droplets allows their amplification independently of one another, thereby preventing the formation of chimeric by-products and reducing the overall amplification bias $[4,7,10]$. For preparative-scale applications, to obtain the purified PCR product after thermocycling, the sample is typically processed to remove the oil and detergents employed for emulsion preparation. This is currently done using hazardous organic solvents like diethyl ether (DEE) and butanol to break the emulsion, followed by purification of PCR products using silica-based columns $[4,7,10,12,13]$. Moreover, extra steps are required to completely remove these chemicals because even trace amounts can interfere with various downstream applications.

To address these issues, we have developed two simpler methods that do not use hazardous organic solvents, and compared their efficiency with a conventional method for breaking the emulsion and subsequent PCR product purification. Based on this, we have proposed a single-step silica column-based 'Quick ePCR extraction protocol' [14]. The conventional method (spin + DEE + column) 

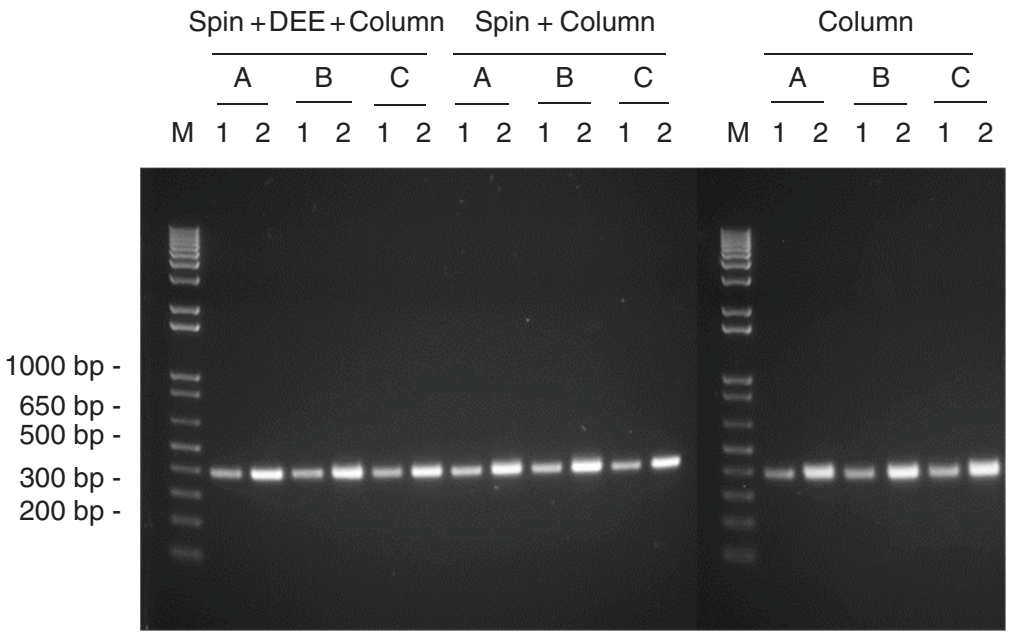

Figure 1. Optimization of the process for extraction and purification of PCR products after emulsion PCR. After PCR, the emulsion was extracted using three different protocols, namely, Protocol-1: Spin+DEE+Column, Protocol-2: Spin+Column, and Protocol-3: Column (Quick ePCR extraction protocol). Each extraction was performed in triplicate (A, B and C) and two different volumes of purified PCR product were analyzed (Lane 1, $5 \mu$ l ePCR product; Lane 2, $10 \mu \mathrm{l}$ ePCR product).

DEE: Diethyl ether.

\begin{tabular}{lll} 
Table 1. Concentration of PCR products purified using three extraction protocols. & \\
\hline Method for extraction & Concentration with Nanodrop $(\mathrm{ng} / \mu \mathrm{l})$ & Concentration with Qubit $(\mathrm{ng} / \mu \mathrm{l})$ \\
\hline Diethyl ether & $9.9 \pm 0.14$ & $9.8 \pm 0.14$ \\
\hline Spin + column & $9.7 \pm 0.28$ & $9.6 \pm 0.27$ \\
\hline Column only (Quick ePCR extraction protocol) & $10.2 \pm 0.51$ & $10.1 \pm 0.53$
\end{tabular}

The concentrations were estimated using the Nanodrop 2000c spectrophotometer and Qubit Fluorometer 2.0 (Thermo Fisher Scientific, MA, USA) employing the dsDNA HS kit. The values reported are the average of three replicates \pm SD

\begin{tabular}{|c|c|c|c|c|c|}
\hline \multirow[t]{2}{*}{ Number } & \multirow[t]{2}{*}{ Construct } & \multicolumn{2}{|c|}{ Electroporation efficiency (per $\mu$ g DNA) } & \multicolumn{2}{|c|}{ Number of correct recombinants } \\
\hline & & $\begin{array}{l}\text { Quick ePCR extraction } \\
\text { protocol }\end{array}$ & Conventional PCR & $\begin{array}{l}\text { Quick ePCR extraction } \\
\text { protocol }\end{array}$ & Conventional PCR \\
\hline 1 & pVMAKHuAb1184scFv002 & $\sim 3 \times 10^{7}$ & $\sim 3 \times 10^{7}$ & $6 / 6$ & $6 / 6$ \\
\hline 2 & pVMAKHuAb1190scFv002 & $\sim 3 \times 10^{7}$ & $\sim 3 \times 10^{7}$ & $6 / 6$ & $6 / 6$ \\
\hline
\end{tabular}

The ePCR amplicons purified using the Quick ePCR extraction protocol (employing QIAquick PCR purification kit) or cPCR amplicons purified using QIAquick PCR purification kit were cloned in an expression vector and the electroporation efficiency was determined. Six random clones for each construct were screened using colony PCR followed by DNA sequencing.

involves centrifugation of the ePCR mixture at $13,000 \times g$ to separate excess oil, followed by breakage of the emulsion using watersaturated DEE, removal of DEE using a centrifugal evaporator, and purification of the PCR products using QIAquick silica-based spin column as described by the manufacturer [15]. Our first new method (spin + column) avoids the use of DEE, but involves centrifugation of the emulsion to remove the overlaid oil, followed by the breakage of the emulsion using QIA PB buffer containing guanidine hydrochloride and isopropanol, and subsequent PCR purification on QIAquick spin columns [15]. The second new method ('Quick ePCR extraction protocol') involves the direct addition of QIA PB buffer to the mixture after ePCR for breakage of the emulsion, followed by purification on QIAquick spin columns. The results show that all three methods worked equally well for purification of PCR products after ePCR (Figure 1 \& Table 1). Thus, the Quick ePCR extraction protocol simplifies the process for extracting DNA after ePCR, making it amenable with high-throughput applications.

We evaluated the quality of the PCR products purified using the Quick ePCR extraction protocol for use in downstream applications, such as cloning and next-generation sequencing. For this, DNA encoding two single-chain Fv (scFv) fragments was amplified using ePCR or conventional PCR (CPCR) and was made compatible for restriction enzyme-free cloning using a library-scale method for insert preparation [16]. The fragments were cloned in ScFv expression vector and the comparison of clones obtained revealed no difference between the cloning efficiency of Quick ePCR or cPCR amplified products (Table 2). Moreover, $100 \%$ of clones were found to be recombinants 


\begin{tabular}{|c|c|c|c|}
\hline Run number & Cluster density $\left(\mathrm{K} / \mathrm{mm}^{2}\right)$ & Cluster passing filter & $\begin{array}{l}\text { Percentage of bases with quality score } \\
\text { more than } 30\end{array}$ \\
\hline 1 & $447 \pm 9$ & $86.75 \%$ & $79.8 \%$ \\
\hline 2 & $661 \pm 2$ & $90.65 \%$ & $79.7 \%$ \\
\hline 3 & $794 \pm 2$ & $89.40 \%$ & $75.8 \%$ \\
\hline
\end{tabular}

(A)

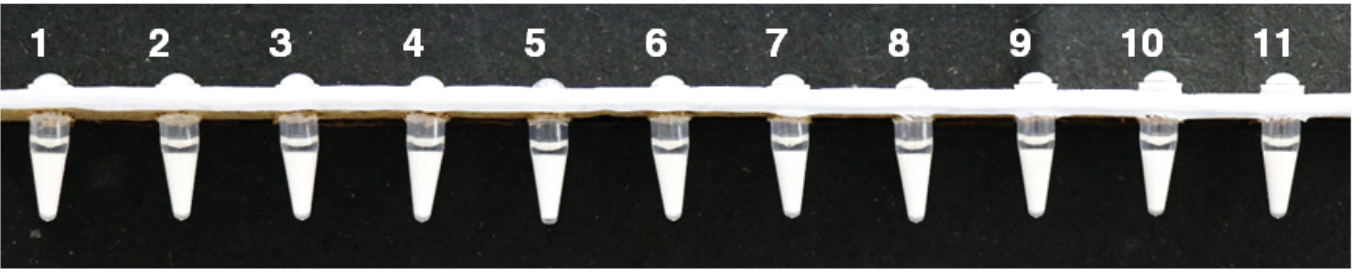

(B)
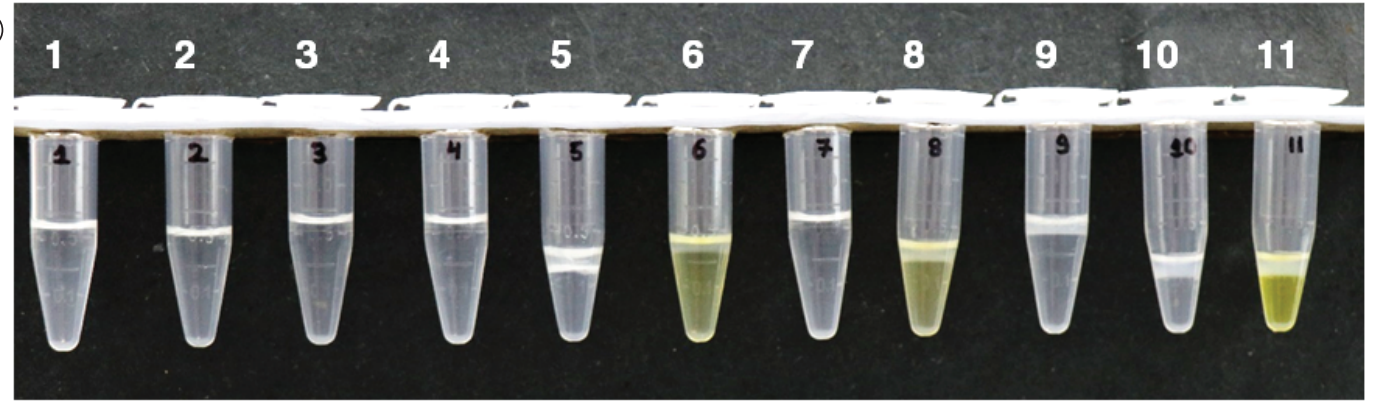

Figure 2. Emulsion PCR before and after breakage with binding buffers provided with commercially available DNA purification kits. (A) Before breakage. (B) After breakage with binding buffer.

encoding the correct scFv sequence in both ePCR and cPCR amplified inserts. The data clearly show that the Quick ePCR extraction protocol does not affect the quality of the PCR products.

Furthermore, the DNA products purified using the Quick ePCR extraction protocol were found suitable for NGS using the Illumina MiSeq platform. To determine the epitopes recognized by different antibodies available in the lab using a phage-displayed gene fragment library, we employed NGS to identify the enriched sequences for the prediction of epitopes after a single round of panning. However, since the number of bound phages after a single round of panning is low, the encoded genes were amplified using a three-step PCR to obtain enough template for NGS. The three-step PCR comprised cPCR followed by two steps of ePCR in which the products were purified using the Quick ePCR extraction protocol. In three independent NGS runs, the 'Clusters Passing Filter' parameter was found to be more than $85 \%$, and high-quality data were obtained with more than $75 \%$ bases carrying $\% \mathrm{Q}>30$, which as per the norms prescribed by Illumina for $2 \times 250$ cycles of paired-end sequencing, indicated that the quality of DNA library purified using the Quick ePCR extraction protocol was suitable for NGS (Table 3) $[17,18]$.

For the optimization of the Quick ePCR extraction protocol and to demonstrate downstream applications of the extracted products, we used reagents and silica-based columns supplied by Qiagen as these are routinely used in our laboratory [15]. To further assess the wide applicability of the Quick ePCR extraction protocol, we evaluated it with 11 commercially available PCR product purification kits (Table 4). We observed that the binding buffers provided with 5 out of 11 kits broke the emulsion completely (kit no. I-IV and VII; Figure 2 \& Table 4), but for the remaining kits, we observed only partial breakage of the emulsion (kit no. V, VI, VIII-IX; Figure 2). The PCR products were purified irrespective of the degree of emulsion breakage; analysis using agarose gel electrophoresis and quantitation using Nanodrop and Qubit revealed variable PCR product yields (Figure 3 \& Table 4). The lower yield with the QIAquick PCR purification kit compared with some other kits indicated that perhaps it was not the most efficient kit for the extraction and purification of ePCR products (Figure 3 \& Table 4). Use of other kits, such as PureLink Quick PCR purification kit (kit no. II; Thermo Fisher Scientific), Monarch PCR and DNA Cleanup kit (kit no. III; NEB), QIAquick Gel extraction kit (kit no. VI; Qiagen), NucleoSpin Gel and PCR Clean-up (kit no. VIII; Macherey-Nagel), Wizard SV Gel and PCR Clean-Up System (kit no. X; Promega) and GeneJET PCR purification kit (kit no. XI; Thermo Scientific) led to higher yields of PCR products despite incomplete breakage of the emulsion with some kits. In the case of kit no. IX, NucleoTraPCR kit (Macherey-Nagel), which employs a silica bead suspension instead of a column, the eluted sample contained oil. Due to the presence of oil, we observed a high sample reading with Nanodrop (based on measurement of absorbance at $280 \mathrm{~nm}$ ) but not 


\begin{tabular}{|c|c|c|c|c|c|c|}
\hline Kit number & Kit & $\begin{array}{l}\text { Volume of binding } \\
\text { buffer (per } 100 \mu \mathrm{I} \\
\text { PCR) }\end{array}$ & Volume of wash buffer & $\begin{array}{l}\text { Concentration with } \\
\text { Nanodrop }\end{array}$ & $\begin{array}{l}\text { Concentration with } \\
\text { Qubit }\end{array}$ & Emulsion breakage \\
\hline I & $\begin{array}{l}\text { QIAquick PCR } \\
\text { purification Kit } \\
\text { (Qiagen) }\end{array}$ & $500 \mu l$ & $700 \mu \mathrm{l}$ & $11.9 \pm 0.0$ & $10.1 \pm 0.9$ & Yes \\
\hline II & $\begin{array}{l}\text { PureLink Quick PCR } \\
\text { purification kit } \\
\text { (Thermo Fisher } \\
\text { Scientific) }\end{array}$ & $400 \mu \mathrm{l}$ & $650 \mu l$ & $27.5 \pm 1.1$ & $23.5 \pm 0.3$ & Yes \\
\hline III & $\begin{array}{l}\text { Monarch PCR and } \\
\text { DNA Cleanup kit (NEB) }\end{array}$ & $500 \mu \mathrm{l}$ & $200 \mu l$ & $20.9 \pm 1.8$ & $20.1 \pm 2.6$ & Yes \\
\hline IV & $\begin{array}{l}\text { DNA Clean \& } \\
\text { Concentrator - } 5 \\
\text { (Zymo Research) }\end{array}$ & $500 \mu \mathrm{l}$ & $200 \mu l$ & $12.3 \pm 1.1$ & $10.6 \pm 0.2$ & Yes \\
\hline V & $\begin{array}{l}\text { QuickClean II PCR } \\
\text { extraction kit } \\
\text { (GenScript) }\end{array}$ & $200 \mu \mathrm{l}$ & $650 \mu l$ & $8.4 \pm 0.8$ & $4.2 \pm 1.1$ & No; partial \\
\hline VI & $\begin{array}{l}\text { QIAquick Gel } \\
\text { extraction kit (Qiagen) }\end{array}$ & $300 \mu l$ & $700 \mu \mathrm{l}$ & $30.7 \pm 3.2$ & $24.6 \pm 1.9$ & No; partial \\
\hline VII & $\begin{array}{l}\text { GenElute PCR } \\
\text { Clean-Up Kit } \\
\text { (Sigma-Aldrich) }\end{array}$ & $500 \mu \mathrm{l}$ & $500 \mu l$ & $11.9 \pm 0.6$ & $10.6 \pm 0.7$ & Yes \\
\hline VIII & $\begin{array}{l}\text { NucleoSpin Gel and } \\
\text { PCR Clean-up } \\
\text { (Macherey-Nagel) }\end{array}$ & $200 \mu \mathrm{l}$ & $700 \mu \mathrm{l}$ & $33.6 \pm 0.8$ & $29.5 \pm 3.3$ & No; partial \\
\hline IX & $\begin{array}{l}\text { NucleoTraPCR } \\
\text { (Macherey-Nagel) }\end{array}$ & $400 \mu l$ & $\begin{array}{l}400 \mu \mathrm{I} \text { NT2, } \\
400 \mu \mathrm{I} \text { NT3, } \\
400 \mu \mathrm{I} \text { NT3 }\end{array}$ & $23.7 \pm 0.0$ & $1.8 \pm 0.0$ & No; partial \\
\hline$x$ & $\begin{array}{l}\text { Wizard SV Gel and } \\
\text { PCR Clean-Up System } \\
\text { (Promega) }\end{array}$ & $100 \mu l$ & $700 \mu \mathrm{l}$ & $57 \pm 7.0$ & $23.4 \pm 2.3$ & No; partial \\
\hline XI & $\begin{array}{l}\text { GeneJET PCR } \\
\text { purification kit } \\
\text { (Thermo Scientific) }\end{array}$ & $100 \mu \mathrm{l}$ & $700 \mu \mathrm{l}$ & $30.7 \pm 1.0$ & $25.7 \pm 0.8$ & No; partial \\
\hline
\end{tabular}

The concentration was estimated using the Nanodrop 2000c spectrophotometer and Qubit Fluorometer 2.0 (Thermo Fisher Scientific, MA, USA) employing the dsDNA HS kit. The values reported are the average of two replicates \pm SD.

with Qubit (based on measurement of fluorescence after specific binding of dye to the DNA) and this finding was confirmed by agarose gel analysis (Figure 3C).

Overall, we have demonstrated that several commercially available PCR product extraction kits can be employed in our Quick ePCR extraction protocol for rapid and easy purification of ePCR products. Our results suggest that the composition of the DNA-binding buffer used plays an important role in emulsion breakage and extraction of ePCR product for direct purification using silica-based columns. However, the composition of the binding buffer supplied with many of the kits that led to complete emulsion breakage is not clearly documented in the literature. As per the available literature, the QIAquick PCR purification kit (kit no. I; Qiagen) and the PureLink Quick PCR purification kit (kit no. II; Thermo Fisher Scientific) both employ binding buffers containing isopropanol, and in our study both kits lead to complete breakage of the emulsion with good recovery of PCR product. However, another kit from Thermo Fisher Scientific, the GeneJET PCR purification kit (kit no. XI), where addition of isopropanol is not reported, did not break the emulsion completely. Therefore the presence of isopropanol in the DNA-binding buffer may be important for emulsion breakage without additional processing.

Furthermore, the quality and downstream utility of the PCR product purified using commercial kits other than the QIAquick PCR purification kit remains to be evaluated.

In summary, we have described a rapid, easy, and user-friendly Quick ePCR extraction protocol for the extraction and purification of ePCR products that involves the use of silica-based PCR purification kits, eliminating the necessity for tedious organic solvent-based extraction. The results clearly show that the quality of product obtained using this protocol (involving direct extraction using silica columns) is comparable with the products obtained using conventional methods and is suitable for routine cloning and NGS applications. This simplified process will make emulsion PCR easy and within the reach of every laboratory and will find use in numerous preparativescale applications that involve the amplification of genes with highly similar or identical sequences, such as antibody gene cloning, aptamer library amplification and NGS, especially 16 S rRNA profiling $[7,10,19]$. 
(A)

$$
\frac{I}{\frac{A}{12} \frac{B}{12}} \frac{A}{\frac{A}{12} \frac{B}{12}} \frac{A}{\frac{A}{12} \frac{B}{12}}
$$

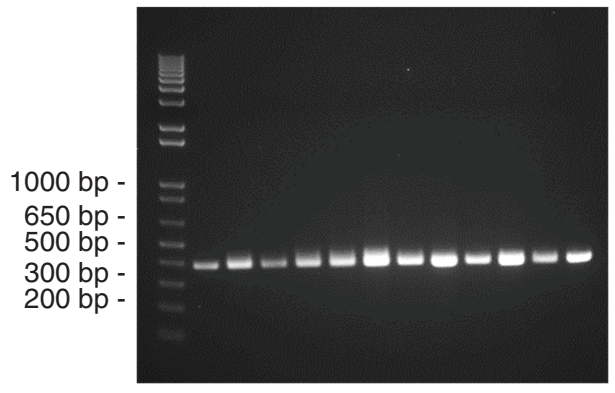

(C)

$$
\frac{\text { VII }}{\frac{A}{12} \frac{B}{12}} \frac{\text { VIII }}{\frac{A}{12} \frac{B}{12}} \frac{\text { IX }}{\frac{A}{12} \frac{B}{12}}
$$

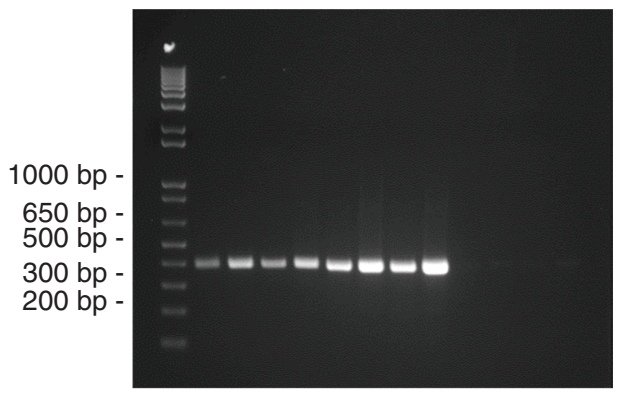

$$
\frac{\mathrm{IV}}{\frac{\mathrm{A}}{12} \frac{\mathrm{B}}{12}} \frac{\mathrm{V}}{\frac{\mathrm{A}}{12} \frac{\mathrm{B}}{12}} \frac{\mathrm{VI}}{\frac{\mathrm{A}}{12} \frac{\mathrm{B}}{12}}
$$
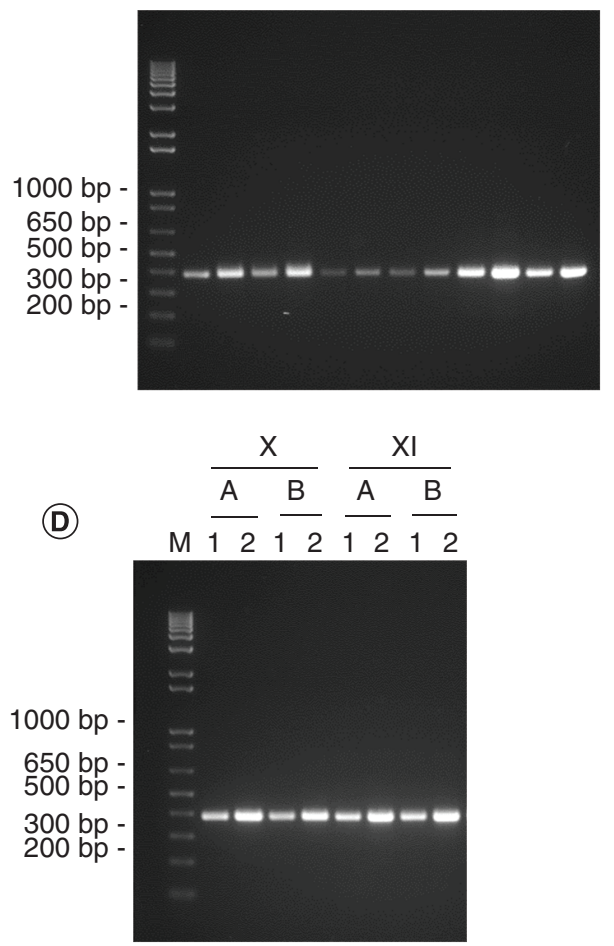

Figure 3. Analysis of PCR products purified using Quick extraction protocol with different commercially available DNA purification kits. After PCR, the emulsion was extracted using Quick extraction protocol with different commercially available kits (I-XI). Each extraction was performed in duplicate $-A$ and B, and different volumes of purified PCR product were analyzed (Lane 1, $5 \mu$ l ePCR product; Lane 2, $10 \mu$ l ePCR product). (A) Kit I: QIAquick PCR purification Kit (Qiagen); Kit II: PureLink Quick PCR purification kit (Thermo Fisher Scientific); Kit III: Monarch PCR and DNA Cleanup kit (NEB). (B) Kit IV: DNA Clean \& Concentrator - 5 (Zymo Research); Kit V: QuickClean II PCR extraction kit (GenScript); Kit VI: QIAquick Gel extraction kit (Qiagen). (C) Kit VII: GenElute PCR Clean-Up Kit (Sigma-Aldrich); Kit VIII: NucleoSpin Gel and PCR Clean-up (Macherey-Nagel); Kit IX: NucleoTraPCR (Macherey-Nagel). (D) Kit X: Wizard SV Gel and PCR Clean-Up System (Promega); Kit XI: GeneJET PCR purification kit (Thermo Scientific).

\section{Supplementary data}

To view the supplementary data that accompany this paper please visit the journal website at: www.futurescience.com/doi/suppl/10.2144/btn-2019-0161

\section{Author contributions}

V Verma conceived and designed the work, acquired, analyzed and interpreted the data, drafted the manuscript, had final approval of the published version and agrees to be accountable for all aspects of the work in ensuring that questions related to the accuracy or integrity of any part of the work are appropriately investigated and resolved. A Gupta conceived and designed the work, had final approval of the published version and agrees to be accountable for all aspects of the work in ensuring that questions related to the accuracy or integrity of any part of the work are appropriately investigated and resolved. V Chaudhary conceived and designed the work, interpreted the data, acquired funding, drafted the manuscript, had final approval of the published version and agrees to be accountable for all aspects of the work in ensuring that questions related to the accuracy or integrity of any part of the work are appropriately investigated and resolved.

\section{Acknowledgments}

The authors acknowledge instrumentation and technical support by S Das at DBT-supported Genomic facility at University of Delhi South Campus.

\section{Financial \& competing interests disclosure}

The authors acknowledge funding from the CSIR (NMITLI), Department of Biotechnology (DBT), grant number BT/INF/22/SP23286/2017, BT/MED/29/SP19222/2017 and a DST-Purse grant through the University of Delhi. The work described in this article is protected by an Indian patent application no. 201811038157 and WIPO (PCT) no. PCT/IN2019/050742. The authors have 
no other relevant affiliations or financial involvement with any organization or entity with a financial interest in or financial conflict with the subject matter or materials discussed in the manuscript apart from those disclosed.

No writing assistance was utilized in the production of this manuscript.

\section{Open access}

This work is licensed under the Attribution-NonCommercial-NoDerivatives 4.0 Unported License. To view a copy of this license, visit http://creativecommons.org/licenses/by-nc-nd/4.0/

\section{References}

1. Tawfik DS, Griffiths AD. Man-made cell-like compartments for molecular evolution. Nat Biotechnol. 16(7), $652-656$ (1998).

2. Ghadessy FJ, Ong JL, Holliger P. Directed evolution of polymerase function by compartmentalized self-replication. Proc. Natl Acad. Sci. USA 98(8), 4552-4557 (2001).

3. Diehl F, Li M, He Y, Kinzler KW, Vogelstein B, Dressman D. BEAMing: single-molecule PCR on microparticles in water-in-oil emulsions. Nat. Methods 3(7), 551-559 (2006).

4. Williams R, Peisajovich SG, Miller OJ, Magdassi S, Tawfik DS, Griffiths AD. Amplification of complex gene libraries by emulsion PCR. Nat. Methods 3(7), 545-550 (2006).

5. Ge Q, Liu Z, Bai Y, Zhang D, Yu P, Lu Z. Emulsion PCR-based method to detect Y chromosome microdeletions. Anal. Biochem. 367(2), 173-178 (2007).

6. Hindson BJ, Ness KD, Masquelier DA et al. High-throughput droplet digital PCR system for absolute quantitation of DNA copy number. Anal. Chem. 83(22), 8604-8610 (2011).

7. Shao K, Ding W, Wang F, Li H, Ma D, Wang H. Emulsion PCR: a high efficient way of PCR amplification of random DNA libraries in aptamer selection. PLoS ONE 6(9), e24910 (2011).

8. Sumida T, Yanagawa H, Doi N. In vitro selection of fab fragments by mRNA display and gene-linking emulsion PCR. J. Nucleic Acids 2012, 371379 (2012).

9. Dekosky BJ, Ippolito GC, Deschner RP et al. High-throughput sequencing of the paired human immunoglobulin heavy and light chain repertoire. Nat. Biotechnol. 31(2), 166-169 (2013).

10. Boers SA, Hays JP, Jansen R. Micelle PCR reduces chimera formation in 16S rRNA profiling of complex microbial DNA mixtures. Sci. Rep. 5, 14181 (2015).

11. Spencer SJ, Tamminen MV, Preheim SP et al. Massively parallel sequencing of single cells by epicPCR links functional genes with phylogenetic markers. ISME J. 10(2), 427-436 (2016).

12. Boers SA, Hays JP, Jansen R. Novel micelle PCR-based method for accurate, sensitive and quantitative microbiota profiling. Sci. Rep. 7, 45536 (2017).

13. Schutze T, Rubelt F, Repkow J et al. A streamlined protocol for emulsion polymerase chain reaction and subsequent purification. Anal. Biochem. 410(1), 155-157 (2011).

14. Protocols.io. Quick Emulsion PCR Extraction Protocol. https://www.protocols.io/view/quick-emulsion-pcr-extraction-protocol-bcjpiumn

15. Qiagen. QIAquick Spin Handbook: QIAquick PCR Purification Kit. Qiagen (EN-HB-1196-002) (2015). https://www.qiagen.com/us/resources/resourcedetail?id=3987caa3986-ef3928-398 4abd-3927e-d5759d986658\&lang=en

16. Chaudhary VK, Shrivastava N, Verma V et al. Rapid restriction enzyme-free cloning of PCR products: a high-throughput method applicable for library construction. PLoS ONE 9(10), e111538 (2014).

17. Illumina. MiSeq ${ }^{T M}$ System (2018). https://www.illumina.com/documents/products/datasheets/datasheet_miseq.pdf

18. Illumina. Optimizing Cluster Density on Illumina Sequencing Systems (2016). https://www.illumina.com/content/dam/illumina-marketing/documents/products/other/miseq-overcluster ing-primer-770-2014-038.pdf

19. Kugler J, Wilke S, Meier D et al. Generation and analysis of the improved human HAL9/10 antibody phage display libraries. BMC Biotechnol. 15, 10 (2015). 